\title{
CLASSIFICAÇÃO DOS PESQUISADORES/CONSULTORES DA ÁREA DE ENFERMAGEM NO CNPQ: contribuição para um banco de dados
}

\author{
Isabel Amélia Costa Mendes* \\ Joséte Luzia Leite** \\ Regina Maria dos Santos*** \\ Maria auxiliadora Trevizan ${ }^{\star \star \star \star}$
}

\section{Resumo}

Trata-se de análise das temáticas e sub-áreas de conhecimento nas quais pesquisadores de enfermagem do CNPq estão incluídos, tomando por base os projetos julgados no período 2002/ 2003. Os objetivos foram apresentar a distribuição dos pesquisadores de acordo com a atual classificação da área de Enfermagem adotada pelo CNPq e discutir a representatividade dos pesquisadores por sub-área de conhecimento. Os resultados evidenciaram as sub-áreas predominantes de pesquisa da categoria: fundamentos dos processos de cuidar, seguido da área de assistência em enfermagem do adulto. Revela ainda a concentração dos pesquisadores e aponta para necessidade de estabelecimento de estratégias de inclusão e de incentivo à demanda por financiamento à pesquisa por eles desenvolvida. Ressalta, por fim, a importância de atualização das sub-áreas em consonância com o fortalecimento da produção científica. Descritores: enfermagem; pesquisadores de enfermagem; CNPq; Sistema de Ciência e Tecnologia

\section{Abstract}

This study is an analysis of the themes and the knowledge subareas where nursing researchers from CNPq (Brazilian Council for Technological and Scientific Development) are included, based on the projects assessed over the períod from 2002 through 2003. Their goals were to present the distribution of researchers according to their present classification in the Nursing area adopted by CNPq and discuss the representativity of the researchers from this knowledge area. Results evidenced that the predominant subareas regarding research in this category were: fundamentais of the care process, followed by the area of adult nursing care. This study also revealed the existing concentration of researchers and pointed out for the need to establish inclusion strategies and to stimulate the return on financial resources to the research they develop. Authors emphasize the importance of an update in the subareas as well as a strengthening effort in scientific production. Descriptors: nursing; nursing researchers; CNPq; science and technology system

Title: Classification of $\mathrm{CNPq}$ researchers/ consultants in the nursing area: contribution to a data bank

\section{Resumen}

Se trata del análisis de las temáticas y sub-áreas de conocimiento, en las cuales los investigadores de enfermería dei CNPq están íncluídos, tomándose como base los proyectos juzgados durante 2002 y 2003. Los objetivos han sido presentar la distribución de los ínvestigadores de acuerdo a la actual clasificación del área de Enfermería. Además, discutir la representatividad de los investigadores por sub-áreas de conocimiento. Los resultados han evidenciado las sub-áreas que predominan en la investigación de la categoría: los fundamentos de los procesos de cuidar. y a seguir el área de la asistencia en enfermería dei adulto. Muestra, aún, la concentración de los investigadores y apunta hacia la necesidad de establecer estrategias de inclusión e incentivo. Sobresale la importancia de actualizar las sub-áreas de la producción científica.

Descriptores: enfermería; investigadores de enfermería; $\mathrm{CNPq}$

Titulo: Clasificación de los investigadores/ consultores del área de enfermería en el CNPq: contribución para un banco de datos

\section{Considerações Iniciais}

Pretende-se neste trabalho apresentar a classificação dos pesquisadores de enfermagem cadastrados no CNPq conforme suas linhas de pesquisa e sub-áreas do conhecimento de enfermagem. Sabemos que esta importante agência de fomento vem delineando tendências e apontando para estudos que enfatizam a multidisciplinaridade e o pluralismo tanto teórico como metodológico na construção das linhas e áreas de p'esquisa(1); porém, acreditamos que esta multidisciplinaridade e esse pluralismo serão construídos na aproximação de diferentes saberes que se reúnem para compreender, explicar e ou intervir - quando possível - na realidade. Justamente porque assim entendemos esta questão, defendemos a idéia de que é importante e necessário delinear a posição dos pesquisadores, especificamente da área de Enfermagem, contribuindo para disponibilizar um banco de dados e informações úteis para consulta.

Considerando que esta agência incluiu a Enfermagem como área de conhecimento na grande área da Saúde e que vem ao longo dos últimos 20 anos expandindo suas cotas de investimento para produção científica desta área, pensamos que é relevante contribuir com a sua organização técnico- cientifica, oferecendo subsídios para a tomada de decisão acerca do universo de estudiosos que estão aptos a atuar e que atuam como consultores, uma vez que eles são detentores de Bolsa de Produtividade ( $\mathrm{PQ})$, concedidas pela própria agência, otimizando o tempo, a disponibilidade e adequação aos projetos que Ihes são destinados a avaliar.

Por outro lado, é necessário compreender que a inclusão da Área de Enfermagem como campo de produção de conhecimento nesta agência de fomento foi uma conquista da categoria a partir dos esforços de seus membros, inseridos na sua associação de classe, a Associação Brasileira de Enfermagem, e nos programas de pós-graduação, desde que estes foram criados, tendo como palco principal de discussão os eventos da categoria. Daí porque sentimos necessidade de recuperar, mesmo que sucintamente, o processo de inclusão da Enfermagem como área de conhecimento na Agência, bem como de apontar particularidades do funcionamento do CNPq naquilo que se reveste de interesse para a Enfermagem.

\section{A Enfermagem no CNPq}

A pesquisa tem sido uma área de contínuo crescimento e investimento por parte da Enfermagem brasileira. O caminho

* Enfermeira. Pesquisador 1A do CNPq; Professor Titular. Membro do Capítulo Rho Upsilon da Sociedade Honorífica Sigma Theta Tau Internacional. Diretora da Escola de Enfermagem de Ribeirão Preto/USP - Centro Colaborador da Oragnização Mundial de Saúde para o desenvolvimento da Pesquisa em Enfermagem. Representante da Área de Enfermagem no CNPq 2001-2004. Coordenadora do CAMs-CNPq

** Enfermeria. Dra. em Enfermagem. Professora Emérita da UFERJ (ex UNIRIO), Pesquisadora do CNPq. Membro do Capítulo Rho Upsilon da Sociedade Honorífica Sigma Theta Tau Internacional.

*** Enfermeira. Dra. em Enfermagem. Professora Adjunta IV da UFAL. Membro do Nuphebras/EEAN/UFRJ.

${ }^{* * \star \star}$ Enfermeira. Pesquisado 1A do CNPq. Professor Titular da EERP/USp - Centro Colaborador da Organização Mundial de Saúde para o desenvolvimento da Pesquisa em Enfermagem. Membro do Capítulo Rho Upsilon da Sociedade Honorífica Sigma Theta Tau Internacional.

E-mail do autor: iamendes@eerp.usp.br 
percorrido até o patamar atual foi longo e difícil. Já no $1^{\circ}$ Congresso Brasileiro de Enfermagem (10 CBEn), realizado em 1947, exigia-se que as enfermeiras se iniciassem na pesquisa, deflagrando um processo de aprendizagem no mister de produzir conhecimento que era uma necessidade para a consolidação da profissão. Há quase 40 anos, em 1964, o tema central do $14^{\circ} \mathrm{CBEn}$, realizado na cidade de Salvador, foi "Enfermagem em Pesquisa", por sugestão da coordenadora da Comissão de Temas, prof. Maria Ivete Ribeiro de Oliveira(2). Naquele momento as pesquisas ainda não eram expressivas, em termos quantitativos, para concorrer com outras áreas, necessitando ainda de incremento. Em 1967 este tema volta a ser repetido e a partir de 1970 tornou-se uma constante em todos os Congressos, quando já se discutia a organização dos primeiros cursos de pós-graduação(3).

Com o início dos cursos de mestrado, em 1972, a pesquisa em Enfermagem tomou vulto, ampliando seu corpo de produção científica a partir dos resultados das dissertações defendidas, mas só em 1985 essa produção foi suficiente para incluir a Enfermagem entre as áreas de conhecimento do CNPq, passando os pesquisadores da área a concorrer com seus projetos aos recursos de fomento à pesquisa (1). Deste modo, quando este órgão criou o Diretório dos Grupos de Pesquisa em 1992, as enfermeiras registraram seus grupos de estudos e trabalhos que hoje totalizam, segundo o Censo de 15/07/ 2002, 231 grupos, com 657 linhas de pesquisa e 1537 pesquisadores $^{(3)}$. Essa informação dá idéia do peso desta conquista e do quanto é significativo para a área estar incluída nesta agência de fomento à pesquisa. É importante salientar que a base de dados consultada contém informações sobre todos os grupos de pesquisa em atividade no país, e que hoje totalizam 15158 grupos distribuídos em todas as áreas de conhecimento atendidas pela Agência ${ }^{(4)}$.

\subsection{O funcionamento do CNPq}

Inicialmente, descrevemos sucintamente a origem do CNPq, enquanto agência de fomento à pesquisa, e depois tentaremos explicar resumidamente a lógica de seu funcionamento, a partir das instâncias percorridas pelos projetos e como se dá a escolha dos consultores que examinam as solicitações e recomendam a concessão de bolsas ${ }^{(5)}$.

A idéia de criar uma entidade governamental específica para fomentar o desenvolvimento científico remonta ao ano de 1920 quando os integrantes da Academia Brasileira de Ciências (ABC) comentavam o assunto como conseqüência da Primeira Guerra Mundial. Em 1931, a ABC dá a sugestão formal ao governo e este não se pronuncia a respeito. Em maio de 1936, o Presidente Getúlio Vargas enviou mensagem específica ao Congresso sobre essa idéia, mas não teve a acolhida desejada por parte dos parlamentares. A partir da Segunda Guerra Mundial, graças ao avanço das tecnologias bélica, aérea e farmacêutica, houve um despertar não só no Brasil, mas em todos os países, da preocupação sobre a importância da investigação científica, principalmente em energia nuclear. A bomba atômica era a prova real e assustadora do poder que a ciência poderia atribuir ao homem, ficando claro que a pesquisa deveria passar a ser vista pelos governos como uma área a ser alvo de investimento, principalmente se fosse acompanhada de uma agenda de prioridades que enfocasse problemas de difícil resolução ou que significasse desenvolvímento científico e tecnológico. Depois desses esforços, em maio de 1946 o almirante Álvaro Alberto da Motta e Silva, representante brasileiro na Comissão de Energia Atômica do Conselho de Segurança da recém criada Organização das Nações Unidas (ONU), propôs ao governo, por intermédio da $\mathrm{ABC}$, a criação do $\mathrm{CNPq}$, denominado à época de Conselho Nacional de Pesquisa. Dois anos mais tarde, em 1948, o projeto sobre a criação do CNPq era apresentado à Câmara dos Deputados, porém, somente em 1949, o presidente Eurico Gaspar Outra indicou uma Comissão para apresentar um Ante Projeto de Lei sobre sua criação. Depois de discutido em diversas Comissões, em 15 de janeiro de 1951 foi criado o CNPq, através da Lei n01310/51, chamada pelo Almirante Álvaro Alberto de Lei Aurea de Pesquisa do Brasi(/(6). Hoje, denominado de Conselho Nacional de Desenvolvimento Científico e Tecnológico, conserva a mesma sigla, embora tenha assumido maiores proporções e tenha conservado antigas dificuldades na hora de definir o seu orçamento anual.

Atualmente, é dirigido por um Conselho Deliberativo (CD) integrado pelos Presidentes do CNPq, da FINEP e da Coordenação de Aperfeiçoamento de Pessoal de Nivel Superior (CAPES), o Secretário Executivo do Ministério da Ciência e Tecnologia, o Vice-Presidente do CNPq, seis representantes da Comunidade Cientifica, três da Comunidade Tecnológica, três da Comunidade Empresarial e um representante dos servidores. Este Conselho Deliberativo (CD) tem à sua disposição um conjunto de estruturas internas no estilo Comitê, cuja função é de assessoria nas decisões relativas à distribuição dos recursos financeiros e na determinação da política nacional de articulação e fomento à pesquisa. Os órgãos colegiados são os 37 Comitês Assessores (CAS) e o Comitê Multidisciplinar de Articulação (CMA), descritos a seguir:

\subsubsection{Comitês de Assessores (CA)}

O CNPq tem uma estrutura de trabalho composta pelos membros dos Comitês Assessores (constituídos após consulta à comunidade científica) organizados por áreas de conhecimento, responsáveis pela avaliação de projetos de solicitação de apoio à pesquisa e de formação de recursos humanos $(\mathrm{RH})$. Esses comitês ainda avaliam os projetos que chegam pelo fluxo contínuo solicitando recursos para pós-doutorado no Brasil e no exterior (PDE), visitas de estágios, auxílios a viagens, entre outros.

Para esclarecer o percurso dos projetos que chegam ao balcão da agência em busca de financiamento, deve-se registrar que eles são verificados pela área técnica do órgão que analisa se o projeto e o seu autor estão em conformidade com as exigências internas. Depois desta verificação, os considerados aptos são direcionados pelos técnicos a dois consultores ad-Hoc, que emitem parecer sobre o mérito do projeto. Essas providências são formalizadas em processos que são encaminhados para serem analisados pelo CA. Esse fluxo dos processos foi um dos principais motivadores do presente estudo e confere a ele a relevância que the atribuímos.

O Comitê Assessor responde pela recomendação da distribuição das cotas de bolsa e de recursos, segundo critérios de relevância, produção científica, formação de recursos humanos, com base no parecer dos consultores e dos critérios técnico-cientificos da proposta. A Enfermagem integra o Comitê Assessor Multidisciplinar de Saúde (CAMS), único que é multidisciplinar e a.sua coordenação no presente exercício está sendo desenvolvida pela representante da Enfermagem. As áreas que integram o CAMS são: Odontologia, Enfermagem, Educação Física, Fisioterapia, Fonoaudiologia e Terapia Ocupacional.

\subsubsection{Comitê Multidisciplinar de Articulação (CMA)}

Este Comitê é constituído por 15 membros dos CAs, sendo um colegiado que assessora a diretoria executiva do CNPq nos assuntos de competência de fomento à pesquisa e desenvolvimento de $\mathrm{RH}$. No momento de elaboração deste estudo o CMA está em reformulação, sem previsão de como será (re)constituído e como funcionará.

\subsubsection{Consultores ad-Hoc}

São especialistas do mais alto nível, em sua maioria bolsistas de Produtividade em Pesquisa, que analisam o mérito científico e a viabilidade técnica dos projetos de pesquisa 
submetidos à agência em forma de solicitação de bolsas e auxílios, através de encaminhamento pelos técnicos da agência. Uma vez esclarecidos esses pontos, retomamos a questão que nos prepusemos a investigar.

\section{Problema em Foco}

A experiência tem mostrado que as informações que pretendemos reunir neste estudo não estão facilmente disponíveis ou organizadas no próprio órgão e nem nas áreas de conhecimento. Isto ocorre, de um lado, pelo próprio dinamismo da ciência brasileira, e/ou pela falta de uma política de gestão de conhecimento e, por outro lado, pela ínsuficiência de informação do próprio pesquisador aos órgãos de pesquisa sobre qual a área temática em que está realmente atualizado, através de palavras-chave que possam ser utilizadas pelos técnicos para acioná-lo para atividade de consultoria. Com isso, não raras vezes os projetos são analisados pelos consultores que não detêm as melhores condições para analisá-los. Isto não ocorre por falta de mérito do próprio consultor, mas simplesmente porque seus estudos e sua produção científica evoluíram e podem estar agora localizados em outra especialidade. A insuficiência de informações atualizadas gera dificuldades para todos os envolvidos. Outra fonte geradora de tais dificuldades é a falta de atualização das sub-áreas no contexto de todas as áreas de conhecimento nos organismos de Ciência e Tecnologia no Brasil.

Justamente por conhecer a dinâmica de funcionamento desta agência governamental de fomento à pesquisa e saber como é importante que a Enfermagem tenha os seus projetos analisados por consultores da própria área e especialistas na sub-área do projeto submetido, julgamos necessário visualizar a distribuição dos consultores ad Hoc em condições de fazer' frente às necessidades tanto do CNPq como da Enfermagem, otimizando o aproveitamento dos recursos que sabidamente já são insuficientes para a demanda desta área do conhecimento.

Neste sentido, a classificação que pretendemos apresentar vem preencher uma lacuna no sistema de informação sobre pesquisa e pesquisadores da Enfermagem brasileira, daí porque temos como objetivos:

Apresentar a distribuição dos pesquisadores/ consultores do CNPq de acordo com a atual classificação nas sub-áreas de Enfermagem adotadas pelo órgão;

Discutir a representatividade e especialidade dos pesquisadores/consultores, por sub-área de conhecimento tendo em vista o crescimento e desenvolvimento da Enfermagem.

\section{Metodologia}

Para atingir os objetivos propostos, optou-se por um estudo exploratório descritivo cujo recorte temporal foi de 2002 a 2003. A população foi constituída pelo universo dos pesquisadores bem como suas linhas de pesquisa atualmente cadastrados no CNPq. O levantamento das linhas de pesquisa ou áreas temáticas de atuação dos pesquisadores cadastrados no $\mathrm{CNPq}$ foi feito com base no resultado do julgamento dos projetos da área, realizado em julho de 2003. Metodologicamente, percorremos os seguintes passos:

Primeira etapa: relacionou-se os pesquisadores constantes do banco de dados on-line do CNPq de agosto de 2003, com bolsas concedidas naquele julgamento, bem como aqueles em curso. No período em estudo os pesquisadores são em número de 90(7).

Segunda etapa: efetuou-se buscas nos sites das universidades dos pesquisadores, suas linhas de pesquisa e publicações afins, cotejando as informações adquiridas com os demais dados anteriormente coletados.

Terceira etapa: na presença de dúvidas, consultou-se os programas de pós-graduação, ou o próprio pesquisador, para fins de confirmação ou esclarecimento sobre a área temática do pesquisador.

Quarta etapa: agrupou-se as temáticas por sub-áreas de conhecimento extraídas das áreas de atuação cadsatradas, sendo que para aquelas que não constam da classificação atualmente adotada pelo CNPq, efetuou-se uma aproximação conceitual e operacional, exclusivamente para efeito de análise dos dados.

Tomou-se como fontes primárias os bancos de dados on-line do CNPq e ossites das universidades dos consultores. As fontes secundárias foram capturadas através de sucessivas leituras de artigos sobre assuntos correlatos para compreender e revelar a realidade de onde foi destacado o objeto de estudo, a fim de contextualizar a análise dos dados.

\section{Análise e discussão dos Resultados}

No período em estudo os pesquisadores são em número de 90, conforme detectado no site do CNPq em agosto de 2003, o que reflete um quantitativo ainda muito reduzido. Isto se explica, talvez, pelas dificuldades advindas das exigências constantes nos critérios de seleção da grande área da Saúde, tanto para aceitação dos projetos como para inclusão de recém-doutores entre os habilitados para concorrer aos recursos do órgão ou ainda, pela insatisfação dos doutores quando enviam os seus projetos para avaliação e recebem resultado desfavorável(5l. Para tentar reverter esta situação e ampliar o contingente de pesquisadores temos realizado estratégias de estímulo e orientação com vistas ao aumento da demanda.

De posse do quantitativo de pesquisadores cadastrados, tratamos de identificá-los conforme sua região geográfica e instituição, como pode se ver na tabela 1.

Os dados das Tabelas 1 e 2 revelam a alta concentração de pesquisadores na Região Sudeste, o que não é um fato desconhecido, porém, apontam para o aparecimento de pesquisadores cadastrados na Região Centro Oeste e um discreto crescimento do número de pesquisadores na Região Nordeste em relação ao ano de 2001(5). Continua sendo ainda no eixo Rio/São Paulo que está localizado o maior número de pesquisadores, uma vez que aí se localizam as Universidades que detém o maior número de programas de pós-graduação stricto sensu, como é o caso da EERP/USP $(35,6 \%)$, EEUSP $(17,8 \%)$, UFRJ $(13,4 \%)$ e UNIFESP $(7,8 \%)$, totalizando 67 pesquisadores ou $74,4 \%$ do total dos pesquisadores em Enfermagem do país. Se forem acrescidas as demais Universidades do eixo, esse número chega a 72 pesquisadores ou $80,0 \%$ do total.

Por outro lado, os dados da Tabela 2 acabam por responder a uma das questões levantadas: onde se encontram os pesquisadores de Enfermagem cadastrados no CNPq. Hoje, pode-se dizer que eles estão ligados a Universidades Públicas, Federais ou Estaduais, majoritariamente as de São Paulo e Rio de Janeiro. Não obstante, torna-se visível a distribuição dos pesquisadores pelo território nacional, deixando em aberto algumas questões: Como ampliar essa distribuição para as demais regiões do país? Que estratégias poderão conduzir o processo de superação das dificuldades imp'ostas pelos critérios de inclusão da Grande Área, para os recém-doutores? $\mathrm{E}$, mesmo para os que não são mais jovens doutores, como seria possível sensibilizá-los, a fim de tornar possível a ampliação dos pesquisadores cadastrados nas demais áreas geográficas?

Outro dado significativo é a distribuição dos pesquisadores cadastrados segundo sua categoria e nível. A classificação dos pesquisadores cadastrados no CNPq, no período considerado para o estudo, está apresentada na Tabela 3.

Os dados da Tabela 3 evidenciam que a maioria dos pesquisadores está classificada na categoria 2, Nível 8 (25,6\%), sendo esse o segundo nível após a entrada do pesquisador no sistema. Enquanto isso, somente $16,7 \%$ são classificados 
Tabela 1 - Distribuição dos pesquisadores cadastrados no CNPq por região do País e Categoria. Brasília, agosto de 2003.

\begin{tabular}{ccccccc}
\hline Categ.I & \multicolumn{7}{c}{ Regiões } \\
\cline { 2 - 7 } Nível & SE & S & N & ND & C-O & Total \\
\hline IA & 9 & 0 & 0 & 0 & 0 & 9 \\
IB & 5 & 0 & 0 & 1 & 0 & 6 \\
IC & 17 & 1 & 0 & 1 & 0 & 19 \\
IIA & 12 & 0 & 0 & 2 & 0 & 14 \\
IIB & 17 & 3 & 0 & 2 & 1 & 23 \\
IIC & 14 & 3 & 0 & 2 & 0 & 19 \\
\hline Total & $\mathbf{7 4}$ & $\mathbf{7}$ & $\mathbf{0}$ & $\mathbf{8}$ & $\mathbf{1}$ & $\mathbf{9 0}$ \\
\hline
\end{tabular}

Tabela 2 - Distribuição dos pesquisadores cadastrados no CNPq de acordo com a Instituição de Ensino superior (IES) de origem. Brasília, agosto de 2003.

\begin{tabular}{lcc}
\hline IES do pesquisador & $\mathbf{f}$ & \% \\
\hline USP - ERP & 32 & 35,6 \\
USP - EE & 16 & 17,8 \\
UFRJ & 12 & 13,4 \\
UNIFESP & 7 & 7,8 \\
UFSC & 5 & 5,6 \\
UFCE & 4 & 4,4 \\
UERJ & 3 & 3,3 \\
FURG & 2 & 2,2 \\
UFMG & 1 & 1,1 \\
UECE & 1 & 1,1 \\
UNIRIO & 1 & 1,1 \\
UFPB & 1 & 1,1 \\
UFES & 1 & 1,1 \\
UNIFOR & 1 & 1,1 \\
UFPEL & 1 & 1,1 \\
UNICAMPO & 1 & 1,1 \\
UFG & 1 & 1,1 \\
\hline Total & $\mathbf{9 0}$ & $\mathbf{1 0 0 , 0}$ \\
\hline
\end{tabular}

Tabela 3 - Distribuição dos pesquisadores de enfermagem cadastrados no $\mathrm{CNPq}$ de acordo com a classificação no níveis da carreira do Pesquisador CNPq. Brasília, agosto de 2003.

\begin{tabular}{lcc}
\hline Classificação & $\mathbf{f}$ & $\mathbf{\%}$ \\
\hline Categoria 1 Nível A & 9 & 10,0 \\
Categoria 1 Nível B & 6 & 6,7 \\
Categoria 1 Nível C & 19 & 21,1 \\
Categoria 2 Nível A & 14 & 15,5 \\
Categoria 2 Nível B & 23 & 25,6 \\
Categoria 2 Nível C & 19 & 21,1 \\
\hline Total & $\mathbf{9 0}$ & $\mathbf{1 0 0 , 0}$ \\
\hline
\end{tabular}

como pesquisadores experientes, porque estão nos Níveis $1 \mathrm{~A}$ e $1 \mathrm{~B}$. Isso quer dizer que a grande maioria dos pesquisadores ainda se encontra no início do percurso na carreira de pesquisador. Deve-se esclarecer que muitos dos pesquisadores que ingressaram recentemente no sistema, não são inexperientes na prática da pesquisa. Muitos outros são doutores há bastante tempo, são profissionais com produção reconhecida em quantidade e qualidade, mas que, pelas mais diversas razões, não fazem parte da carreira de pesquisador, demonstrando a falta de tradição da Enfermagem na captação de recursos para pesquisa.

Sobre esse problema, cabe, ao nosso ver, duas reflexões: A Enfermagem brasileira se encontra num patamar de desenvolvimento tal que é imprescindível investir maciçamente em pesquisa, inclusive contribuindo com a prioridade mundial para a área que é o desenvolvimento de estudos da prática de Enfermagem baseada em evidências, testando suas teorias, com a finalidade de consolidar, articular e ampliar seu corpo próprio de conhecimento. Deve, portanto contar com a participação de todos os pesquisadores que se disponham a compartilhar este processo num esforço coletivo, o que nos indicaria o engajamento de todos os pesquisadores, antigos e novos, experientes ou não, independente do esforço que seja necessário para superar os critérios de inclusão. A demanda qualificada traduzida pelos projetos dos enfermeiros-pesquisadores ainda não-incluídos nesta carreira do CNPq viria contribuir como demonstrativo ao órgão (e à própria classe) do potencial da enfermagem e da necessidade de ampliação das cotas de bolsa produtividade em pesquisa.

A segunda reflexão diz respeito ao grau de dificuldade que cada pesquisador enfrenta para estar em condições de concorrer aos recursos disponibilizados pelas agências de fomento. Isso implica em superar suas limitações, principalmente quanto a produção científica ao tempo em que tece suas análises críticas sobre o processo, os critérios e os recursos com que os projetos disputam em desigualdade de condições na grande área da saúde.

No que diz respeito à classificação dos pesquisadores e suas linhas de pesquisa por sub-área de conhecimento, limitamo-nos aos que estão atualmente cadastrados no CNPq. Estamos cientes de que os pesquisadores não cadastrados também têm seus saberes, suas linhas de pesquisa, sua especialidade; porém, o nosso propósito guarda relação com aqueles que são cadastrados como pesquisadores de produtividade na referida agência, e por conseqüência atuam como consultores ad-Hoc, esperando até que a leitura desses dados sensibilize novos cadastros, aumentando assim o número dos estudiosos pertencentes ao seleto grupo estudado. Todavia, o fato de termos optado pelos pesquisadores cadastrados não impede que os demais, caso seja desejado, não possam ser localizados e incluídos nesta classificação, uma vez que ampliar o leque de pesquisas e pesquisadores na Enfermagem é a motivação deste trabalho.

Por outro lado, aceitamos que o conceito de linha de pesquisa pode variar conforme o olhar do pesquisador e por esta razão adotamos neste trabalho a definição do CNPq, assim descrita: temas aglutinados de estudos científicos e/ou tecnológicos que se fundamentam em tradição investigativa, de onde se originam projetos cujos resultados guardam relação entre si(B). Da mesma forma, para este trabalho, tomamos como Área de Conhecimento um conjunto de conhecimentos que guardam coerência e afinidade entre si e que se refere ao saber produzido para a produção de algum bem ou serviço necessário à sobrevivência da humanidade. Levamos em conta as áreas de conhecimento adotadas pelo CNPq, entre as quais se encontra a Área de Enfermagem, dentro da Grande Área da Saúde.

Assim sendo, acatamos o princípio da liberdade do pesquisador que se permite produzir em mais de uma linha de pesquisa, considerando que, através deste artifício, muito trabalhoso, reconhecemos, é possível construir um quantum expressivo $d, e$ estudos, suficiente para tornar a área reconhecidamente produtiva, a ponto de ser necessário dispor de uma classificação das sub-áreas que compõem a Área da Enfermagem. Tal necessidade foi suprida pelas providências das representantes de área que, através de seus estudos e de suas recomendações, contribuíram para a elaboração das sub-áreas existentes, embora já sintamos há algum tempo dificuldades em acomodar, na classificação em vigor, a totalidade dos projetos recebidos.

Uma vez cumprida a quarta etapa da coleta de dados anteriormente descrita, elaboramos um primeiro quadro onde foram distribuídas as linhas de pesquisa dos pesquisadores, o sistema de cadastramento de pesquisadores do CNPq permite a inclusão de no máximo seis áreas de atuação com possibilidade de inserção das especialidades. Assim, 


\begin{tabular}{|c|l|c|}
\hline Ordem & \multicolumn{1}{|c|}{ Sub-áreas } & $\mathbf{n}$ \\
\hline 1 & Enfermagem Médico-Cirúrgica & 44 \\
\hline 2 & Enfermagem Obstétrica & 12 \\
\hline 3 & Enfermagem Pediátrica & 10 \\
\hline 4 & Enfermagem Psiquiátrica & 12 \\
\hline 5 & Enfermagem em Doenças contagiosas & 5 \\
\hline 6 & Enfermagem em Saúde Pública & 37 \\
\hline 7 & $\begin{array}{l}\text { Outras - incluídas as que não puderam } \\
\text { ser enquadradas nas sub-áreas } \\
\text { existentes }\end{array}$ & 62 \\
\hline
\end{tabular}

Quadro I - Número de registros cadastrados como área de atuação dos Pesquisadores em Enfermagem em cada sub-área/especialidade em vigor no CNPq.

\begin{tabular}{|c|c|c|}
\hline Ordem & Área Temática elou Linha de Pesquisa & $\mathbf{n}$ \\
\hline 1 & $\begin{array}{l}\text { Assistência de Enfermagem à Saúde do } \\
\text { Adulto e Idoso (inclui estudos das } \\
\text { doenças crônico-degenerativas e } \\
\text { processos de cuidado do adulto e do } \\
\text { idoso }\end{array}$ & 30 \\
\hline 2 & $\begin{array}{l}\text { Assistência de Enfermagem na } \\
\text { promoção, preservação e recuperação } \\
\text { da saúde da mulher e estudos das } \\
\text { questões de sexualidade e gênero }\end{array}$ & 13 \\
\hline 3 & $\begin{array}{l}\text { Assistência de Enfermagem ao neonato, } \\
\text { criança e adolescente }\end{array}$ & 10 \\
\hline 4 & $\begin{array}{l}\text { Assistência de Enfermagem em } \\
\text { processos de preservação e recuperação } \\
\text { da saúde mental }\end{array}$ & 6 \\
\hline 5 & $\begin{array}{l}\text { Assistência de Enfermagem em Saúde } \\
\text { Coletiva, estudos epidemiológicos, } \\
\text { estudos das questões sociais e de } \\
\text { políticas públicas de saúde e } \\
\text { enfermagem }\end{array}$ & 16 \\
\hline 6 & $\begin{array}{l}\text { Fundamentos teóricos, epistemológicos, } \\
\text { metodológicos, históricos, éticos e } \\
\text { biológicos do processo de cuidar }\end{array}$ & 40 \\
\hline 7 & $\begin{array}{l}\text { Administração, gestão e gerência em } \\
\text { Saúde e em Enfermagem }\end{array}$ & 12 \\
\hline 8 & $\begin{array}{l}\text { Metodologias de pesquisa aplicadas à } \\
\text { Enfermagem }\end{array}$ & 3 \\
\hline 9 & $\begin{array}{l}\text { Processos e Métodos de Educação em } \\
\text { Enfermagem }\end{array}$ & 5 \\
\hline 10 & $\begin{array}{l}\text { Outros processos especializados de } \\
\text { cuidar em enfermagem relativos à } \\
\text { situações não contempladas }\end{array}$ & 7 \\
\hline
\end{tabular}

Quadro II - Proposta de classificação das áreas temáticas e/ou linhas de pesquisa para cadastramento Pesquisadores da Área de Enfermagem, agosto de 2003.

identificamos 62 registros de especialidades não contempladas nas sub-áreas existentes, indicando que muitos pesquisadores não puderam ter suas linhas de pesquisa ou sua produção científica localizada em nenhuma das sub-áreas existentes, o que, certamente contribui para dificultar o trabalho de distribuição dos projetos, por parte da área técnica do CNPq, para os consultores ad-Hoc.

Aqueles que prosseguiram produzindo e nominando sua linha de pesquisa/ou área de estudo, ou seu grupo de trabalho ou núcleo de estudo, com a nomenclatura usual e em vigor, foram facilmente identificados e classificados, destacando-se a área dê Enfermagem Médico-Cirúrgica como sendo a mais contemplada (44), reunindo estudos sobre Assistência de Enfermagem à pessoa adulta, idosa, homens ou mulheres, em situação clinica, cirúrgica ou em Emergências, numa lógica mais aproximada do modelo biomédico, insuficiente para incluir estudos não clinicos, mas que dizem respeito à questão sob outros paradigmas.

Quando analisamos os dados do Quadro I em relação aos projetos submetidos ao CNPq, tomando como base estudo anterior $^{(5)}$ verificamos que, de fato, não é possível identificar qual a distribuição dos pesquisadores segundo a classificação de sub-áreas do CNPq. Por outro lado, a categoria também tem dificuldade em identificar os estudos dos pesquisadores; nem os alunos dos diversos níveis de formação podem facilmente consultar referências, se tomarem por base esta classificação. Se este processo é difícil entre os que compõem a categoria, como esperar que outras pessoas, nas mais diversas circunstâncias, possam identificar a produção da Enfermagem e que julgamento poderão fazer da produção assim classificada? Qual o conceito e referência que se tem da produção da Enfermagem, quando se analisa da forma como está distribuída? Enfim, a questão mais premente é: Como esperar que a área técnica do CNPq direcione o projeto para o consultor certo, ou seja, um especialista no tema?

Essas interrogações se colocam ao verificar a situação da categoria outras, onde se pode incluir todos os estudos, por se tratar do indeterminado, do que foge à norma, ou seja, onde se pode arrolar a produção científica mais atual, onde estão os estudos que mostram a diversidade e a profundidade de investigação alcançada pela profissão.

Acreditando ter ficado visível a insuficiência da versão atual e o grau de urgência da modificação requerida, a fim de facilitar o julgamento dos projetos recebidos pelos técnicos, procuramos incluir os itens arrolados na categoria outras, agrupando-os por linhas de pesquisa ou áreas temáticas. Derivou-se daí o Quadro 11 que traduz uma nova opção de cadastramento dos pesquisadores em cada sub-área, a quem os projetos poderão ser enviados para análise e parecer prévio.

Assim, o quantitativo de áreas temáticas e/ou linhas de pesquisa foi obtido dos dados cadastrados nas sub-áreasl especialidades dos pesquisadores (Quadro I) depois de renomeado com base na nova proposta de classificação das áreas temáticas e/ou linhas de pesquisa (Quadro II).

Os dados do Quadro 11 revelam que existe maior número de linhas de pesquisa e de áreas temáticas voltadas para os Fundamentos teóricos, epistemológicos, metodológicos, históricos, éticos e biológicos do processo de cuidar (40), enquanto que a área de Metodologias da Pesquisa aplicadas à Enfermagem congregou menor número de estudos (03). Analisando-se esses dados, verifica-se que a enfermagem, embora continue investindo muito em estudos sobre a saúde do adulto, com ênfase nas doenças crônico-degenerativas, avançando para estudos que dizem respeito a esse grupo de pessoas em outras perspectivas, sob a forma de estudos epidemiológicos, estudos sobre as questões sociais, está investindo fortemente em pesquisas sobre os fundamentos do processo de cuidar. Isso revela o encontro com a maturidade científica da área, a exploração metodológica de seus métodos de cuidar, teorizando e criticando seus pressupostos filosóficos e epistemológicos. Por outro lado, esta nova distribuição das linhas e áreas temáticas dos pesquisadores favoreceu a visualização de que a enfermagem tem apresentado diversidade de abordagens, deixando de pensar o seu trabalho somente na perspectiva da assistência individual.

Neste reordenamento das linhas e áreas temáticas dos pesquisadores foi possível detectar outras áreas que estão sendo exploradas através de pesquisa, avançando do modelo biomédico para outras inquietações, aparecendo estudos voltados para questões da saúde mental, questões de gênero 
e sexualidade, que trazem à tona objetos de estudos que abordam relações interpessoais sejam elas permeadas ou não de relações de poder. Nesta condição, fica mais fácil perceber a representatividade dos pesquisadores em cada sub-área, ao mesmo tempo em que se observa suas especialidades podendo ser mais fácil distribuir mais acertadamente os projetos entre os consultores ad-Hoc. Reconhecemos que será necessário um esforço para manter disponível na agência uma relação que integre o nome dos pesquisadores com as suas respectivas linhas de pesquisa ou área temática do seu domínio, para consulta imediata.

Os resultados deste estudo e as reflexões deles originadas permite-nos alertar os pesquisadores, atuais e futuros, sobre a importância e necessidade de informar ao órgão, através de palavras-chave, sua real especialidade. Isto permitirá à área técnica encaminhar processos de competência do consultor para avaliação, redundando em rapidez, eficácia' e garantia de que os projetos de enfermagem sejam analisados por nossos próprios pares e não por outros profissionais.

\section{Considerações finais}

Tivemos como objetivos deste estudo apresentar a distribuição dos pesquisadores cadastrados no CNPq conforme as sub-áreas atualmente empregadas pelo órgão, discutindo a representatividade e especialidade dos pesquisadores a partir das linhas de pesquisa e áreas temáticas onde desenvolvem seus trabalhos. Ficou evidenciada a insuficiência da classificação atual, demonstrada a diversidade da produção da Enfermagem e a especialidade dos pesquisadores. As sub-áreas da Enfermagem adotadas pelo CNPq já não comportam mais a diversidade de produção dos estudiosos da área, diversidade esta decorrente, ao nosso ver, das diferenças do próprio trabalho de Enfermagem enquanto prática social. Além do mais, pudemos comprovar que as sub-áreas onde houve maior concentração de pesquisadores se referem ao cuidado dos grupos humanos, mostrando a aproximação necessária entre o profissional e a pessoa de quem cuida, deixando perceber que a prática de Enfermagem é geradora de conhecimento novo, privilegiando os espaços onde se desenvolve( ${ }^{(7)}$.

Em assim pensando consideramos muito positiva a diversidade da produção dos pesquisadores; a ampliação de seus objetos de estudo torna-se necessária porque possibilita atender as necessidades dos clientes, o aumento da produção científica fortalecendo a qualificação de recursos humanos, incrementando inclusive a área de produção tecnológica, a qual vem conquistando novos estudiosos ${ }^{(9)}$. Nada mais justo que se ofereça à agência em questão subsídios para que repense a forma como vem classificando e distribuindo os projetos de pesquisa da área, ao tempo em que também se revela como se torna necessário ampliar as cotas de financiamento para os pesquisadores da área.

Torna-se patente a necessidade de inclusão de novas sub-áreas de conhecimento, o estabelecimento de estratégias de incentivo e apoio aos pesquisadores, bem como o desenvolvimento de uma cultura de demanda por financiamento de projetos por parte dos recém-doutores.

\section{Agradecimentos}

Ao Conselho Nacional de Desenvolvimento Científico e Tecnológico-CNPq, à Enfermeira Simone de Godoy e ao Paulo Meio por contribuírem na elaboração deste estudo.

\section{Referências}

1. Mendes IAC, Leite JL. Pesquisa em enfermagem e seu espaço no CNPq. Escola Anna Nery: Revista de Enfermagem, Rio de Janeiro 2000 dez;4(3):389-94.

2. Mancia JR. Maria Ivete: uma personagem da Enfermagem brasileira [editorial] Revista Brasileira de Enfermagem, Brasilia (DF) 2003 maiol jun; 56(3):219.

3. Vieira TT. Produção cientifica em enfermagem no Brasil: 1960-1979 [tese de titular]. Salvador (BA): Escola de Enfermagem da Universidade Federal da Bahia; $1980.200 \mathrm{f}$.

4. Conselho Nacional de Desenvolvimento Cientifico e Tecnológico (BR). Diretório dos Grupos de Pesquisa: censo de 15 jul 2002. [on fine]. Disponível em: URL: hltp://www.cnpq.br. Acessado em: out 2003.

5. Leite JL, Trezza MCSF, Santos RM, Mendes IAC, Felli VEA. Os projetos de pesquisa de enfermagem no CNPq: seu percurso, suas temáticas, suas aderências: 1998/2000. Revista Brasileira de Enfermagem, Brasília (DF) 2001 jan/mar;54(1):81-97.

6. Méis L. O perfil da ciência brasileira. Rio de Janeiro: UFRJ; 1996. $103 p$.

7. Conselho Nacional de Desenvolvimento Cientifico e Tecnológico (BR). Julgamento dos projetos [on line]. Disponível em: URL: hltp:// www.cnpq.br. Acessado em: set 2003.

8. Gutiérrez MGR, Leite JL, Pagliuca LMF, Erdmann AL. Os múltiplos problemas pesquisados e a pesquisa na enfermagem. Revista Brasileira de Enfermagem, Brasília (DF) 2002 set/out;55(5):535-41.

9. Mendes IAC, Leite JL, Trevizan MA, Trezza MCSF, Santos RM. A produção tecnológica e a interface com a Enfermagem. Revista Brasileira de Enfermagem, Brasflia (DF) 2002 set/out;55(5):556-61.

Data de Recebimento: 12/11/2003

Data de Aprovação: 22/12/2003 